\title{
Quantitive systematic review of topically applied non-steroidal anti-inflammatory drugs
}

\author{
R A Moore, M R Tramèr, D Carroll, P J Wiffen, H J McQuay
}

\begin{abstract}
Objective: To review the effectiveness and safety of topical non-steroidal anti-inflammatory drugs in acute and chronic pain conditions.

Design: Quantitive systematic review of randomised controlled trials.

Data sources: 86 trials involving 10160 patients. Main outcome measures: Measures of treatment success approximating at least $50 \%$ reduction in pain, local and systemic adverse effects. Analysis at 1 week for acute and 2 weeks for chronic conditions with relative benefit and number needed to treat.

Results: In acute pain conditions (soft tissue trauma, strains, and sprains) placebo controlled trials had a relative benefit of 1.7 (1.5 to 1.9 ), the number needed to treat was 3.9 (3.4 to 4.4 ). With analysis by drug (at least three trials), ketoprofen (number needed to treat 2.6), felbinac (3.0), ibuprofen (3.5), and piroxicam (4.2) had significant efficacy. Benzydamine and indomethacin were no different from placebo. In chronic pain conditions (osteoarthritis, tendinitis) placebo controlled trials had a relative benefit of 2.0 (1.5 to 2.7); the number needed to treat was 3.1 (2.7 to 3.8). Small trials ( $<40$ treated patients) exaggerated effectiveness of topical non-steroidals by $33 \%$ in acute conditions but not in chronic conditions. There was no relation between trial quality and treatment effect. In both acute and chronic pain local and systemic adverse events and withdrawal from the study related to the drug had a low incidence and were no different from placebo.
\end{abstract}

Conclusion: Topical non-steroidal anti-inflammatory drugs are effective in relieving pain in acute and chronic conditions.

\section{Introduction}

Some topical non-steroidal drugs are available without prescription and are widely advertised for acute and chronic painful conditions. There are 20-24 million prescriptions (predominantly oral) for non-steroidal anti-inflammatory drugs in the United Kingdom each year, $5 \%$ of the NHS total prescriptions. The attributable risk of going to hospital with gastrointestinal problems is 1.3 to $1.6 \%$ annually for regular users of oral non-steroidals. ${ }^{1}$ This raises the question of whether for some patients using oral non-steroidal anti-inflammatory drugs is worse than the disease. ${ }^{2}$
Despite licensed status, there is scepticism that topical non-steroidal anti-inflammatory drugs have any action other than as rubefacients. ${ }^{23}$ This systematic review was undertaken to examine the evidence that topical non-steroidal anti-inflammatory drugs are effective and safe and to determine whether there is evidence for differences between topical preparations.

\section{Methods}

\section{Criteria for inclusion}

We sought reports of randomised controlled trials of topical non-steroidal anti-inflammatory drugs in which pain was an outcome and included those that compared topical non-steroidal anti-inflammatory drug(s) with placebo, with another topical nonsteroidal, or with an oral non-steroidal. A number of different search strategies in Medline (1966 to September 1996), Embase (1981 to September 1996), and the Oxford Pain Relief Database (1950-94) ${ }^{4}$ were used to locate reports by using individual drug name (generic and proprietary) together with the words "administration, topical," "gel," "ointment," "aerosol," “cream," and combinations of these, without restriction to English language. Additional reports were identified from reference lists of retrieved reports and review articles. Librarians and medical directors of the 12 pharmaceutical companies in the United Kingdom identified as marketing topical non-steroidal anti-inflammatory products were asked for reports of randomised controlled trials of their products, including any unpublished reports. Abstracts were not sought. Authors were not contacted.

We included randomised controlled trials of non-steroidal anti-inflammatory drugs with pain as an outcome in acute conditions (strains, sprains, sports injuries) or chronic conditions (arthritis, rheumatism). Those in vaginitis, oral or buccal conditions, thrombophlebitis, or experimental pain settings were not included.

Two of us screened reports to eliminate those without pain outcomes, that were definitely not randomised, or that were abstracts or reviews. Each report was read by all of the authors independently to assess adequacy of randomisation and blinding and to assess description of withdrawals. ${ }^{5}$ The authors met to agree consensus. Reports that were described as randomised were given 1 point, plus a further point if the method of randomisation was described and adequate (such as
Pain Research and Nuffield Department of Anaesthetics, University of Oxford, The

Churchill, Oxford Radcliffe Hospital, Headington, Oxford OX3 7LJ

R A Moore, consultant biochemist M R Tramèr, research fellow D Carroll, senior research nurse P J Wiffen, regional pharmaceutical adviser H J McQuay, clinical reader in pain relief

Correspondence to: Dr Moore andrew.moore@ pru.ox.ac.uk

BMJ 1998;316:333-8 
Table 1 Summary of randomised studies of topical non-steroidal anti-inflammatory drugs in acute and chronic painful conditions

\begin{tabular}{|c|c|c|c|c|c|c|c|}
\hline \multirow[b]{2}{*}{ Trials } & \multirow[b]{2}{*}{ No of trials* } & \multirow[b]{2}{*}{ No of patients } & \multicolumn{5}{|c|}{ Quality score (1-5) } \\
\hline & & & 1 & 2 & 3 & 4 & 5 \\
\hline \multicolumn{8}{|l|}{ Acute pain: } \\
\hline Placebo controlled & $37(34)$ & 3556 & 1 & 6 & 10 & 13 & 7 \\
\hline Active controlled & $24(21)$ & 4171 & 4 & 11 & 4 & 5 & 0 \\
\hline \multicolumn{8}{|l|}{ Chronic pain: } \\
\hline Placebo controlled & $13(12)$ & 1161 & 0 & 3 & 5 & 5 & 0 \\
\hline
\end{tabular}

${ }^{*}$ Numbers in parentheses are those reports with dichotomous outcomes.

a table of random numbers). There had been an earlier agreement that trials without randomisation or with an inadequate randomisation method (without concealment of treatment allocation) would be excluded from further analysis. Reports that were described as blinded were given 1 point, plus a further point if the method of blinding was described and adequate (such as identical appearance of preparation). Reports that described the number of and reasons for withdrawals were given 1 point. Thus the minimum score of an included randomised controlled trial was 1 , the maximum score 5 .

\section{Data collected}

Information about treatment(s) and control(s), condition studied, number of patients randomised and analysed, study design, observation periods, outcome measures used for pain or global evaluation, results of analgesic outcome, local skin irritation, systemic adverse effects, and study withdrawal due to adverse effects was taken from each report by authors meeting to concur.

We defined a clinically relevant successful outcome. A hierarchy of measures was used for extraction which approximated (in order of preference), firstly, patient global judgment (excellent/good); secondly, pain on movement (no pain/slight pain); thirdly, spontaneous pain or pain at rest (no pain/slight pain); and finally, physician global judgment (excellent/good) if defined against a stated scale.

Outcomes not in these categories were defined as "failures." Only information that was available in dichotomous form was used for analysis. The denominator was taken as the number of patients randomised-that is, an intention to treat analysis. For acute conditions we took the effectiveness measure nearest to 1 week after start of treatment and for chronic conditions 2 weeks. Our prior hypotheses were that topical non-steroidals were no better than placebo and that there was no difference between them.

\section{Analysis}

The scatter of success rates with topical non-steroidal against success rate with placebo $^{6}$ was used as a graphical means of exploring the consistency of efficacy and the homogeneity of the data. On such plots a scatter lying predominantly between the line of equality and the axis of the active intervention (topical nonsteroidal) would suggest consistent efficacy with the intervention and relative homogeneity.

Relative risk or benefit (95\% confidence interval) was calculated for pain data from placebo controlled studies by using a random effects model ${ }^{7}$ because the results were heterogeneous. Heterogeneity was assumed when $\mathrm{P}<0.1$. This was done by pooling all data, pooling data for an individual drug for which there were at least three trials, and, for sensitivity analysis, by quality score and size of treatment group. We used a fixed effect model ${ }^{8}$ for the (homogeneous) adverse effect data. A significant improvement over control was assumed when the lower 95\% confidence limit of the relative benefit was $>1$.

Number needed to treat ( $95 \%$ confidence interval) was calculated for effect data. ${ }^{9}{ }^{10}$ The number needed to treat indicates how many patients with acute or chronic pain have to be treated with topical non-steroidal for one of them to achieve a successful outcome who would not have done so with placebo. A significant difference between numbers needed to treat was assumed when confidence intervals did not overlap. Calculations were performed by using EXCEL v 5.0 on a Macintosh 8500/150.

\section{Results}

Searches found 86 reports (10 160 patients) that fulfilled inclusion criteria, 76 of which had dichotomous pain outcomes, including three unpublished reports with 1695 patients from a pharmaceutical company. The number of reports, patients, and the distribution of quality scores is divided by acute or chronic conditions, both placebo controlled and active controlled, in table 1 . Over $75 \%$ of placebo controlled trials had quality scores of 3 or more. Conversely $60 \%$ of active controlled trials had scores of 2 or less. Full details of trial design, outcome measures, and results can be found on the world wide web (http://www. jr2.ox.ac.uk/Bandolier/painres/topic/topic.html).

\section{Acute conditions}

Thirty seven reports of 40 placebo controlled trials of topical non-steroidal anti-inflammatory drugs were found. The mean size of the group treated with topical drug was 47 patients (median 32). Studies were conducted in recent soft tissue injury, sprains, strains, or trauma. Dichotomous pain outcomes were available from 1747 patients with active treatment and 1492 on placebo. An additional 24 reports of 24 trials compared different topical non-steroidal antiinflammatory drugs or formulations or route of administration in 4171 patients. In three studies topical was compared with oral non-steroidal, one of which also had a placebo control.

Relative benefits (95\% confidence intervals) are shown for each placebo controlled trial in figure 1 . Twenty seven of the 37 comparisons showed significant superiority of topical non-steroidal over placebo. The scatter of the proportion of patients with 


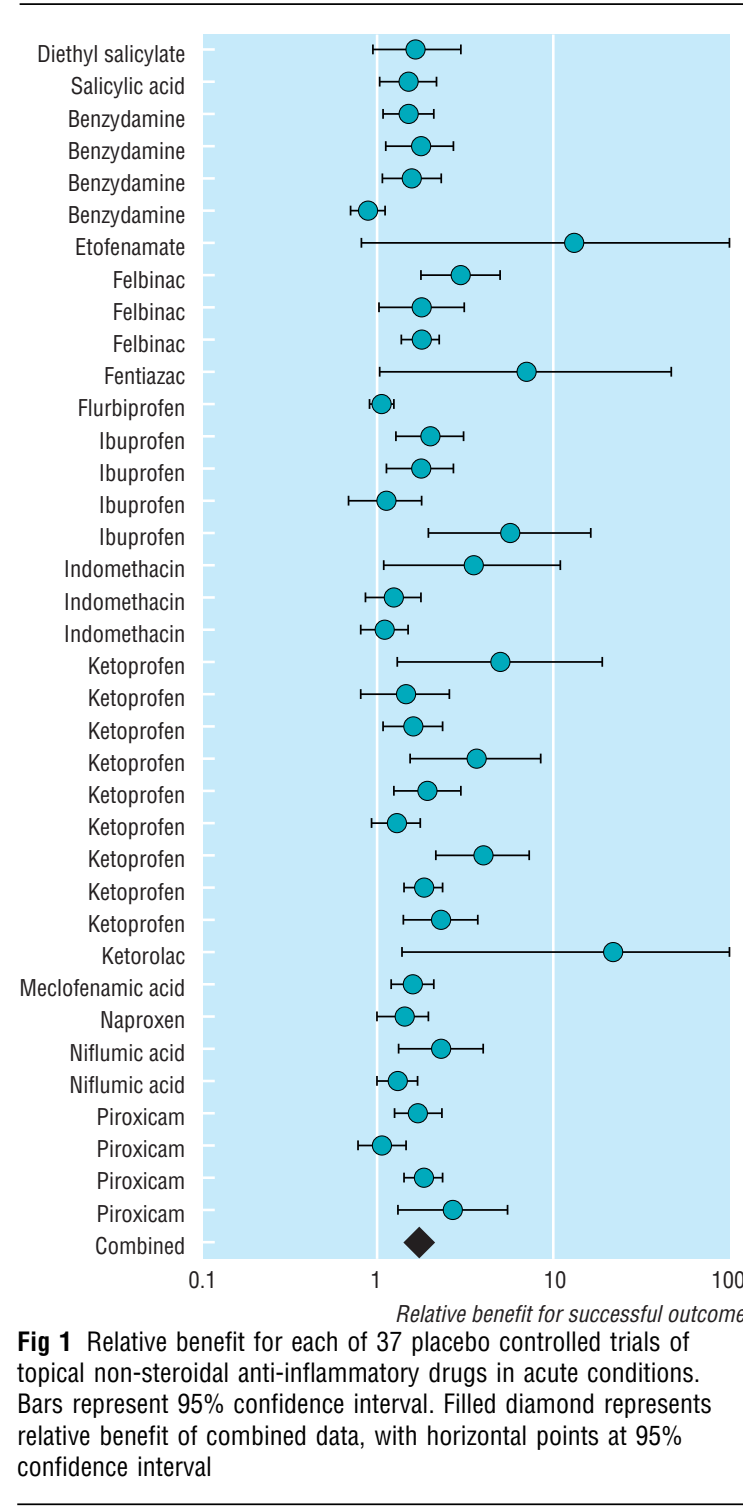

a successful outcome with topical non-steroidal or placebo is shown in figure 2 . Thirty six of the 37 comparisons were in the segment favouring treatment over placebo. The three trials which did not have dichotomous outcomes also reported significant benefit of topical non-steroidal over placebo.

Pooled relative benefit for all 37 comparisons was 1.7 (1.5 to 1.9) and the number needed to treat was 3.9 (3.4 to 4.4) (table 2). The pooling of data from only those trials with a quality score of at least 3 produced the same results. Sensitivity analysis by size of treatment group showed that trials with a group size of fewer than 40 treated patients produced a significantly lower (better) number needed to treat of 2.6 (2.3 to 3.1) than either bigger trials or all trials. Larger trials with 40 to 80 treated patients produced higher (worse) estimates for number needed to treat of 5.0 (3.7 to 7.4) than all trials together, and the largest trials of more than 80 treated patients produced a number needed to treat of 4.6 (3.7 to 5.9).

Pooling data for each drug studied in three or more trials showed ketoprofen, felbinac, ibuprofen, and piroxicam to be significantly superior to placebo with numbers needed to treat of 2.6 to 4.2. Indomethacin and benzydamine were no better than placebo (table 2).
The percentage of patients achieving a successful outcome with active treatment or placebo in all studies in all trials (placebo and active controlled) in acute conditions is shown in figure 3 (lower panel). The range with placebo was $0 \%$ to $80 \%$. With topical non-steroidal it was $30 \%$ to $100 \%$. There was no significant difference in the (low) frequency of local or systemic adverse effects or withdrawal related to tested preparation (table 2 ).

\section{Chronic conditions}

The 13 placebo controlled trials were predominantly in single joint arthritis and rheumatological disorders, with dichotomous outcomes from 547 patients on active treatment and 550 on placebo in 12 trials. Twelve other trials compared different topical non-steroidal anti-inflammatory drugs in 1272 patients. In two of these topical and oral non-steroidal drugs were compared.

Relative benefits (95\% confidence intervals) for each drug compared with placebo are shown in figure 4. Seven of the 12 studies showed significant superiority of topical non-steroidal over placebo. The scatter of the proportion of patients with a successful outcome with topical or placebo is shown in figure 2. All 12 comparisons were in the segment favouring treatment over placebo. The one trial which did not have dichotomous outcomes also reported statistical benefit of topical non-steroidal over placebo.

Pooled relative benefit for all 12 comparisons was 2.0 (1.5 to 2.7) and the number needed to treat was 3.1 (2.7 to 3.8 ) (table 2). Sensitivity analysis by quality score or treatment group size produced no significant change in these estimates; only one trial had a treatment group size of more than 80 patients, and the number needed to treat for this trial was similar to that of the pooled estimate for all trials of more than 40 treated patients. No single topical non-steroidal was tested in as many as three placebo controlled studies

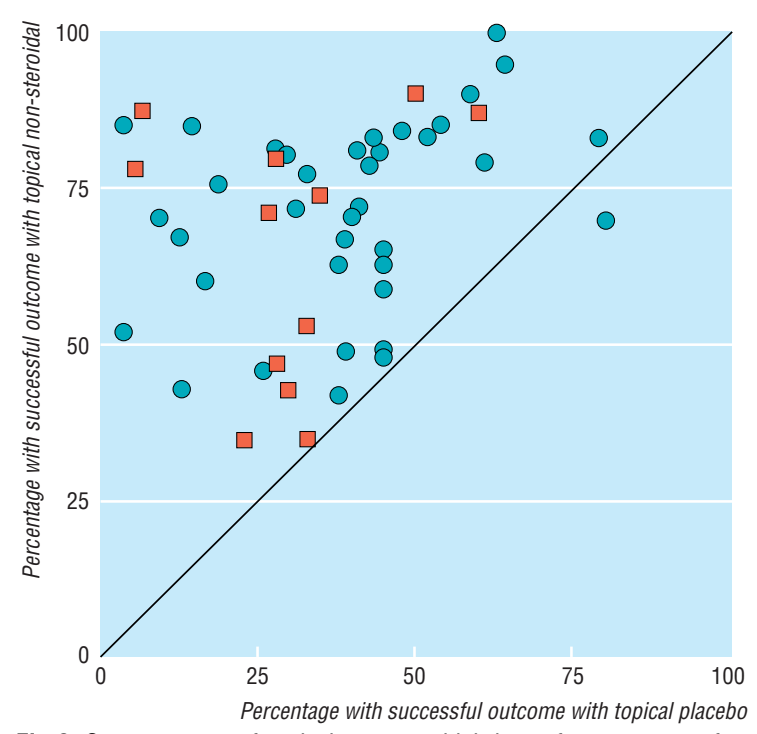

Fig 2 Success rates of topical non-steroidal drugs for treatment of acute $(\bullet)$ and chronic $(\boldsymbol{\square})$ painful conditions. Each symbol represents one comparison of topical non-steroidal with placebo. Percentage with successful outcome was at 1 week for acute and 2 weeks for chronic conditions 
Table 2 Relative benefit and number needed to treat in randomised studies of topical non-steroidal anti-inflammatory drugs in acute and chronic painful conditions

\begin{tabular}{|c|c|c|c|c|c|c|c|}
\hline Condition/drug & $\begin{array}{l}\text { Total } \\
\text { trials }\end{array}$ & $\begin{array}{c}\text { Total } \\
\text { patients }\end{array}$ & $\begin{array}{c}\text { Average No of } \\
\text { treated } \\
\text { patients }\end{array}$ & $\begin{array}{l}\text { Response* }^{*} \\
\text { with placebo } \\
(\%)\end{array}$ & $\begin{array}{l}\text { Response* with } \\
\text { active treatment } \\
(\%)\end{array}$ & $\begin{array}{l}\text { Relative benefit } \\
\quad(95 \% \mathrm{CI})\end{array}$ & $\begin{array}{l}\text { No needed to treat } \\
(95 \% \mathrm{Cl})\end{array}$ \\
\hline \multicolumn{8}{|l|}{ Acute painful conditions } \\
\hline Combined efficacy data & 37 & 3239 & 47 & 39 & 71 & $1.7(1.5$ to 1.9$)$ & $3.9(3.4$ to 4.4$)$ \\
\hline Local adverse effects & & & & 3.0 & 2.6 & $1.2(0.8$ to 1.7$)$ & \\
\hline Systemic adverse effects & & & & 0.7 & 0.8 & $1.0(0.6$ to 1.8$)$ & \\
\hline Withdrawal due to adverse effects & & & & 0.4 & 0.6 & $0.8(0.4$ to 1.4$)$ & \\
\hline Trials of quality score $3-5$ & 30 & 2834 & 52 & 38 & 72 & $1.7(1.5$ to 1.9$)$ & $3.9(3.4$ to 4.4$)$ \\
\hline \multicolumn{8}{|l|}{ Treatment group: } \\
\hline$<40$ & 20 & 933 & 24 & 35 & 76 & $1.9(1.6$ to 2.2$)$ & $2.6(2.3$ to 3.1$)$ \\
\hline $40-80$ & 8 & 810 & 51 & 44 & 66 & 1.6 (1.1 to 2.2 ) & $5.0(3.7$ to 7.4$)$ \\
\hline$>80$ & 7 & 1496 & 123 & 41 & 67 & 1.6 (1.3 to 1.9$)$ & 4.6 (3.7 to 5.9$)$ \\
\hline Ketoprofen & 9 & 724 & 43 & 36 & 74 & $2.0(1.5$ to 2.6$)$ & 2.6 (2.3 to 3.2$)$ \\
\hline Felbinac & 3 & 413 & 70 & 32 & 66 & $2.0(1.5$ to 2.7$)$ & $3.0(2.4$ to 4.1$)$ \\
\hline Ibuprofen & 4 & 284 & 36 & 34 & 70 & $1.9(1.2$ to 3.0$)$ & $3.5(2.5$ to 5.6$)$ \\
\hline Piroxicam & 4 & 589 & 74 & 39 & 69 & $1.6(1.2$ to 2.2$)$ & $4.2(3.1$ to 6.1$)$ \\
\hline Benzydamine & 4 & 245 & 31 & 62 & 84 & $1.4(0.9$ to 2.0$)$ & 6.7 (3.8 to 23) \\
\hline Indomethacin & 3 & 394 & 66 & 32 & 47 & $1.3(0.9$ to 1.8$)$ & $10(5$ to $\infty \dagger)$ \\
\hline \multicolumn{8}{|l|}{ Chronic painful conditions } \\
\hline Combined efficacy data & 12 & 1097 & & 30 & 65 & $2.0(1.5$ to 2.7$)$ & $3.1(2.7$ to 3.8$)$ \\
\hline Local adverse effects & & & & 5.3 & 5.9 & $0.9(0.4$ to 1.7$)$ & \\
\hline Systemic adverse effects & & & & 1.3 & 1.1 & 1.1 (0.5 to 2.3$)$ & \\
\hline Withdrawal due to adverse effects & & & & 0.7 & 0.7 & $1.0(0.4$ to 2.4$)$ & \\
\hline Trials of quality score $3-5$ & 9 & 987 & 55 & 27 & 62 & $2.2(1.5$ to 3.1$)$ & $3.1(2.6$ to 3.8$)$ \\
\hline \multicolumn{8}{|l|}{ Treatment group: } \\
\hline$<40$ patients & 6 & 261 & 22 & 31 & 69 & $2.2(1.5$ to 3.1$)$ & $2.6(2.0$ to 3.6$)$ \\
\hline$>40$ patients & 6 & 836 & 70 & 29 & 61 & $2.0(1.7$ to 2.4$)$ & $3.3(2.8$ to 4.3$)$ \\
\hline
\end{tabular}

${ }^{\star}$ Response is either proportion of patients with successful outcome or of patients with adverse effect. †Indicates that there may be no benefit with treatment over placebo.

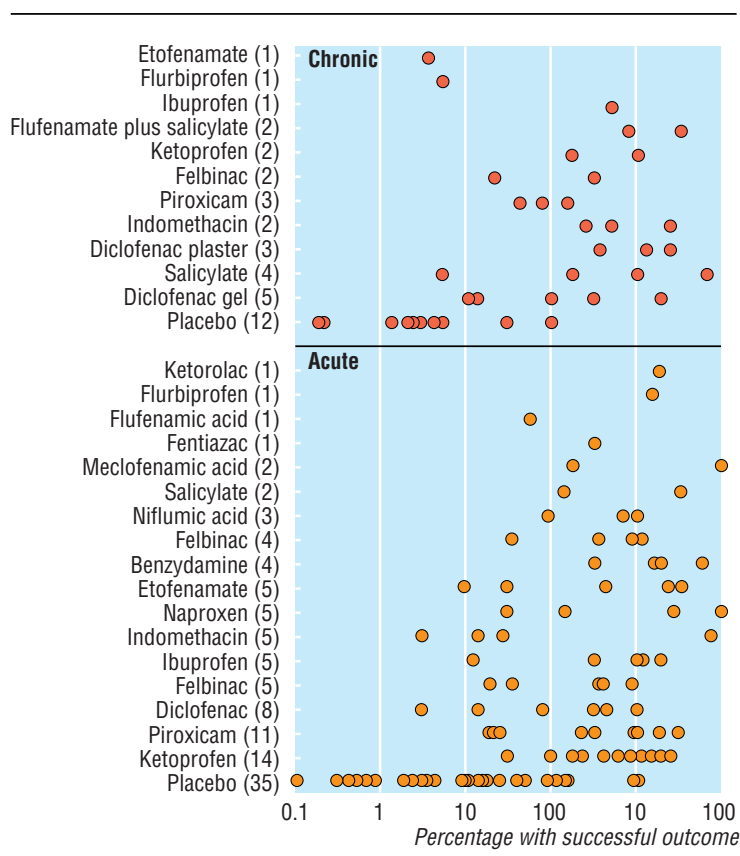

Fig 3 Success rates for single treatment arms from placebo and active controlled trials in acute and chronic conditions for each topical non-steroidal anti-inflammatory drug. Numbers in parentheses indicate number of studies that tested that drug. Percentage with successful outcome was at 1 week for acute and 2 weeks for chronic conditions

and combined estimates could not therefore be calculated for any single drug.

The percentage of patients achieving a successful outcome with active treatment or placebo in all studies in all trials (placebo and active controlled) in chronic conditions is shown in figure 3 (upper panel). The range with placebo was $5 \%$ to $60 \%$. With topical non-steroidal it was $30 \%$ to $95 \%$. There was no significant difference in the (low) frequency of local or systemic adverse effects or withdrawal related to tested drug (table 2).

\section{Comparison with oral non-steroidals}

Five studies compared topical with oral non-steroidal drugs; three in acute conditions ${ }^{11-13}$ and two in chronic conditions. ${ }^{14}{ }^{15}$ None showed significant benefit of oral over topical preparations.

\section{Discussion}

Our results indicate that topical non-steroidals are significantly more effective than placebo for pain relief. This is not just due to rubbing. Placebo preparations were also rubbed on to the affected parts. Topical non-steroidals produced analgesia, which was additional to any effect of rubbing. Topical preparations produced numbers needed to treat in the range of 3 to 5 (see table 2 ), similar to those seen with oral analgesics in moderate or severe pain. ${ }^{16}$ At least one patient in three who uses a topical non-steroidal will achieve a successful outcome who would not have done had they used a placebo.

While this result may surprise some, it is not because the trials were of poor quality. Placebo controlled studies in both acute and chronic conditions had quality scores of 3 or more on a scale of 1 to 5 in over $75 \%$ of reports (see table 1). This is important as trials of lower methodological quality (2 or less with the same validated scale as here) have been shown to have a more favourable outcome. ${ }^{17}$

We judged it sensible to pool data for individual drugs only when there were at least three randomised 


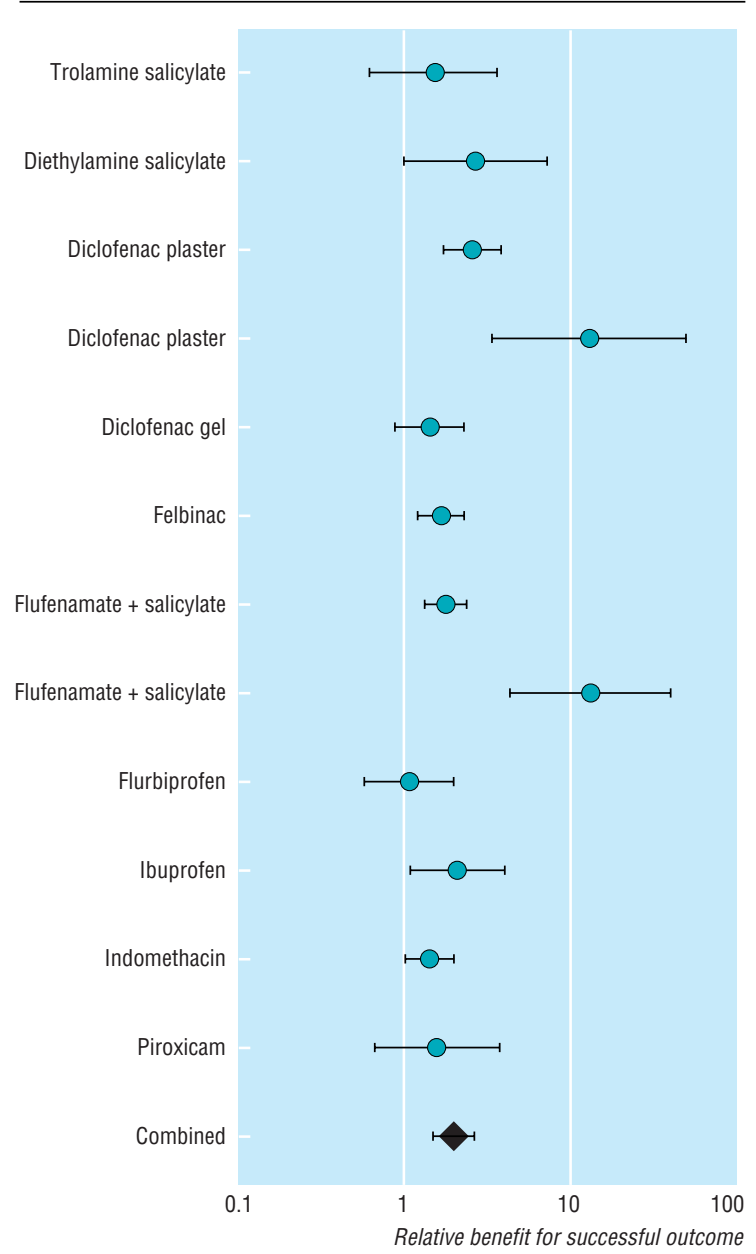

Fig 4 Relative benefit for each of 12 placebo controlled trials of topical non-steroidal anti-inflammatory drugs in chronic conditions. Filled diamond represents relative benefit of combined data and bars represent $95 \%$ confidence interval

trials. In acute conditions there was enough information to make comparisons (table 2). The average response for placebo was similar for individual drugs apart from benzydamine. Ketoprofen, felbinac, ibuprofen, and piroxicam were all significantly superior to placebo, in contrast with indomethacin and benzydamine which were not. Confidence intervals for the number needed to treat for ketoprofen did not overlap with those of benzydamine or indomethacin. There is no clear message as to which of ketoprofen, felbinac, ibuprofen, or piroxicam was best or indeed whether there was any difference in efficacy. They all worked.

Local skin reactions were rare $(3.6 \%)$, and systemic effects were rarer (less than $0.5 \%$ ). Local or systemic adverse effects of sufficient severity to cause withdrawal from the study were also rare $(0.5 \%)$. Adverse effects were no more common than with placebo.

Topical non-steroidal anti-inflammatory drugs have a lower incidence of gastrointestinal adverse effects than the same drugs when they are taken orally. ${ }^{18}$ The low incidence of systemic adverse effects for topical non-steroidal anti-inflammatory drugs probably results from the much lower plasma concentrations from similar doses applied topically to those administered orally. ${ }^{13}{ }^{19}$ Topical application of ibuprofen resulted in measureable tissue concentrations in deep tissue compartments, more than enough to inhibit inflammatory enzymes. ${ }^{19} 20$
It could be argued that these positive results for topical non-steroidals are skewed by publication restricted to positive findings. The funnel plot (figure 5) might be interpreted as showing publication bias. The tendency for smaller trials to produce a larger analgesic effect might be construed as supporting the absence of trials showing no difference between topical non-steroidal and placebo. It is almost impossible to rebut this argument. We made strenuous efforts to unearth unpublished data and contacted all pharmaceutical companies in the United Kingdom that we identified as producing topical non-steroidal products. One company made unpublished data available to us, but others did not feel able to do so.

More important was the empirical evidence that small trials (arbitrarily set at fewer than 40 patients per group as being between the mean and median sizes of 47 and 32 patients per treated group) produced estimates of clinical efficacy exaggerated by 33\% (3.9 minus 2.6/3.9, table 2) in acute painful conditions, with confidence intervals which did not overlap. Because the response rate with placebo was $40 \%$ (see table 2), no calculated number needed to treat could be less than 1.7. ${ }^{21}$ The number needed to treat of five obtained with the treatment group sizes of 40 patients or more should be judged against this.

Trial quality made no difference despite evidence to the contrary from other settings. ${ }^{17}$ Size of treatment group may be an important issue for credibility of estimates of clinical efficacy in treatments, just like randomisation ${ }^{22}{ }^{23}$ and double blinding. ${ }^{22}$ Just as it may be hazardous to change practice on the basis of a single small trial, similarly beware meta-analysis restricted to multiple small trials. ${ }^{24}$

The important research agenda is to identify those patients with chronic disease, particularly elderly patients, who may benefit from using topical rather than oral non-steroidal anti-inflammatory drugs. We need to compare the pain relief and mobility, harm, and cost for these alternatives. The few studies we

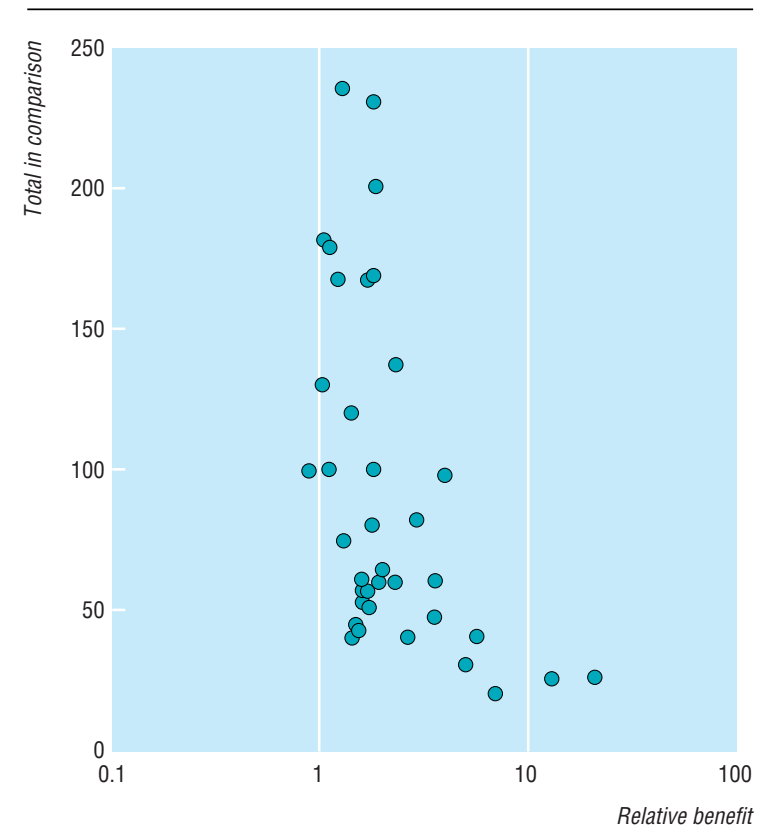

Fig 5 Funnel plot of relative benefit against total number of patients (active plus placebo) for acute trials of topical non-steroidal drugs 
- Topical non-steroidal anti-inflammatory drugs are widely thought to be ineffective, despite licensed status

- To evaluate their effectiveness and safety we conducted a quantitive systematic review of all relevant randomised trials

- In acute conditions like strains and sprains topical non-steroidals were significantly better than placebo over 1 week with a number needed to treat of 3.9 (3.4 to 4.4). For drugs with at least three placebo controlled trials ketoprofen (number needed to treat 2.6), felbinac (3.0), ibuprofen (3.5), and piroxicam (4.2) had significant efficacy

- In chronic conditions like arthritis and rheumatism topical non-steroidals were significantly better than placebo over 2 weeks with a number needed to treat of 3.1 (2.7 to 3.8)

- In both acute and chronic pain local and systemic adverse events and withdrawal related to tested drug had a low incidence and were no different from placebo

identified that compared oral with topical nonsteroidals had inadequate design and power to answer these important questions. In the meantime, the message is that topical non-steroidal antiinflammatory drugs are effective and safe.

The help of librarians from 3M Healthcare, Duphar Laboratories, Lederle Laboratories, Pfizer, and Zyma Healthcare is gratefully acknowledged. Searle (UK) supplied unpublished reports. We also appreciated the stimulating comments of the statistical reviewer of this paper. Bethany Nye provided administrative support.

RAM initiated the project and designed it, participated in searching, read all the papers, and participated in consensus meetings on quality and data extraction, performed data analysis and writing, and approved the final manuscript. MRT read all the papers and participated in consensus meetings on quality and data extraction and approved the final manuscript. DC participated in searching, read all the papers, and participated in consensus meetings on quality and data extraction and approved the final manuscript. PJW read all the papers, and participated in consensus meetings on quality and data extraction and approved the final manuscript. HJM initiated the project and designed it, read all the papers, and participated in consensus meetings on quality and data extraction, performed data analysis and writing, and approved the final manuscript. RAM and HJM are guarantors of the study.

Funding: Pain Research Funds, European Union Biomed 2 contract BMH4 CT95 0172; NHS Research and Development
Health Technology Assessment Programme 94/11/4; UK ORS award (MRT); Proctor and Gamble (Health and Beauty Care); and Searle (UK).

Conflict of interest: Proctor and Gamble and Searle (UK) manufacture non-steroidal anti-inflammatory drugs.

1 Wynne HA, Campbell M. Pharmacoeconomics of non-steroida anti-inflammatory drugs (NSAIDs). PharmacoEconomics 1993;3:107-23.

2 Bateman DN, Kennedy JG. Non-steroidal anti-inflammatory drugs and elderly patients. The medicine may be worse than the disease. $B M$ J 1995;310:817-8.

3 Anonymous. Rational use of NSAIDs for musculoskeletal disorders. Drug Ther Bull 1994;32:91-5.

4 Jadad AR, Carroll D, Moore A, McQuay H. Developing a database of published reports of randomised clinical trials in pain research. Pain 1996;66:239-46.

5 Jadad AR, Moore RA, Carroll D, Jenkinson C, Reynolds DJM, Gavaghan $\mathrm{DJ}$, et al. Assessing the quality of reports of randomized clinical trials: is blinding necessary? Cont Clin Trials 1996;17:1-12.

6 L'Abbé KA, Detsky AS, O’Rourke K. Meta-analysis in clinical research. Ann Intern Med 1987;107:224-33.

DerSimonian R, Laird N. Meta-analysis of clinical trials. Cont Clin Trials $1986 ; 7: 177-88$.

8 Yusuf S, Peto R, Lewis J, Collins R, Sleight P. Beta-blockade during and after myocardial infarction: an overview of the randomized trials. Prog Cardiovasc Dis 1985;27:335-71.

9 Laupacis A, Sackett DL, Roberts RS. An assessment of clinically usefu measures of the consequences of treatment. N Engl J Med 1988;318:1728 33.

10 Cook RJ, Sackett DL. The number needed to treat: a clinically useful measure of treatment effect. $B M J$ 1995;310:452-4.

11 Åkermark C, Forsskåhl B. Topical indomethacin in overuse injuries in athletes. A randomized double blind study comparing Elmetacin with oral indomethacin and placebo. Int J Sport Med 1990;11:393-6.

12 Hosie GAC. The topical NSAID, felbinac, versus oral ibuprofen: a comparison of efficacy in the treatment of acute lower back injury. $\mathrm{Br} J$ Clin Res 1993;4:5-17.

13 Vanderstraeten G, Schuermans P. Study on the effect of etofenamate $10 \%$ cream in comparison with an oral NSAID in strains and sprains due to ports injuries. Acta Belgica Medica Physica 1990;13:139-41.

14 Browning RC, Johson K. Reducing the dose of oral NSAIDs by use of feldene gel: an open study in elderly patients with osteoarthritis. Adv Ther 1994;11:198-206.

15 Golden EL. A double-blind comparison of orally ingested aspirin and a topically applied salicylate cream in the relief of rheumatic pain. Cur Ther Res 1978;24:524-9.

16 McQuay HJ, Moore RA, Justins D. Treating acute pain in hospital. $B M$ J 1997;314:1531-5.

17 Khan KS, Daya S, Jadad AR. The importance of quality of primary studies in producing unbiased systematic reviews. Arch Intern Med 1996;156:661-6.

18 Evans JMM, McMahon A, McGilchrist M, White G, Murray F, McDevitt D et al. Topical non-steroidal anti-inflammatory drugs and admission to hospital for upper gastrointestinal bleeding and perforation: a record linkage case-control study. BMJ 1995;311:22-6.

19 Berner G, Engels B, Vögtle-Junkert U. Percutaneous ibuprofen therapy with Trauma-Dolgit gel: bioequivalence studies. Drugs Exp Clin Res 1989;15:559-64.

20 Treffel P, Gabard B. Feasibility of measuring the biavailability of topica ibuprofen in commercial formulations using drug content in epidermis and a methyl nicotinate skin inflammation assay Skin Pharmacol and a methy

21 McQuay HJ, Moore RA. Using numerical results from systematic reviews in clinical practice. Ann Intern Med 1997;126:712-20.

22 Schulz KF, Chalmers I, Hayes RJ, Altman DG. Empirical evidence of bias: dimensions of methodological quality associated with estimates of treatment effects in controlled trials. JAMA 1995;273:408-12.

23 Carroll $\mathrm{D}$, Tramèr $\mathrm{M}$, McQuay $\mathrm{H}$, Nye $\mathrm{B}$, Moore $\mathrm{A}$. Randomization is important in studies with pain outcomes: systematic review of transcutaneous electrical nerve stimulation in acute postoperative pain. Br J Anaesthes 1996;77:798-803.

24 Egger M, Smith GD. Misleading meta-analysis. Lessons from "an effective, safe, simple" intervention that wasn't. BMJ 1995;310:752-4.

(Accepted 30 June 1997)

\section{Fifty years ago}

\section{The new NHS: Why be fearful?}

The Representative Body last week said No with a determined voice. Some doctors were naturally anxious about the financial risks of saying No. The fear of the paymaster was upon some of them-a fear, no doubt, that Mr. Bevan counts upon in his estimate of the chances of successful resistance by the profession to his Health Service Act in its present form.

Mr. Bevan has the power of the purse- or will have if the profession decides to enter his Service on July 5. But, as Dr. Dain told the Representative Meeting last week, we have only one thing to fear-"and that is that the profession does not know its own mind." It is for medical men and women to state the mind of the medical profession without fear in answering the questions on the plebiscite form to be sent out on Jan. 31. Opposition to the Act will be offered if a sufficient majority which includes 13,000 general practitioners votes No. (Editorial, 17 January 1948, p 104. See also editorial by Gordon Macpherson, 3 January 1998, p 6.) 